(OPSCC) are often younger middle-aged men who may lack the previously significant risk factors. ${ }^{1}$

At the time of diagnosis or after the completion of treatment, patients may have questions and concerns regarding how and why they have become infected with $\mathrm{HPV}^{2}$ as well as needing advice relating to vaccination. In addition, these patients will possibly have partners and young families under care of the same practitioner. These relatives may have anxieties and questions of their own relating to HPV transmission. The treating team will often be the first point of contact for the provision of information. As the number of those treated increases it is likely that the dental practitioner or members of their team will be asked questions that were previously considered taboo and potentially cause embarrassment. The possible psychosocial impact of diagnosis of HPV positive OPSCC should not be overlooked either. Receiving a diagnosis can initiate new feelings of anguish in addition to those coupled with a cancer diagnosis. In cervical cancer, research has shown emotional distress is common amongst women diagnosed with HPV. These feelings include decreased self-esteem, guilt and depression and can generate transmission concerns and intimacy issues. ${ }^{3}$ Investment in advanced communication skills courses for dental teams may aid the practitioner in addressing these topics. Early signposting to medical practitioners and support systems could also be of benefit.

M. Dillon, D. J. Smith, A. Kanatas, Leeds

1. Rates of mouth cancer increase to all time high. $B D J$ Team January 2016. Available at: http://www.nature. com/articles/bdjteam20162 (accessed May 2016).

2. Hancocks S. HPV vaccine for boys. Br Dent J 2014; 216: 1 .

3. McCaffery K, Waller J, Nazroo J, Wardle J. Social and psychological impact of HPV testing in cervical screening: a qualitative study. Sex Transm Infect 2006; 82: 169-174.

DOI: 10.1038/sj.bdj.2016.357

\section{Misleading association}

Sir, the title of the letter Oral cancer: Link with early coitus (BDJ 2016; 220: 279280) suggests a link which is misleading since it is oral sex that is associated with human papilloma virus (HPV), not early coitus. $^{1}$

HPV is associated with between 12-63\% of all oropharyngeal cancers and prognoses of HPV associated non-cervical cancers are better than HPV-negative noncervical cancers. ${ }^{2}$ Engaging in orogenital sex with multiple sex partners is associated with HPVassociated oropharyngeal cancer. ${ }^{3}$ Oral HPV is found three times more commonly in men than women; 8-40\% of HPV-positive oropharyngeal squamous cell cancer patients report never having had oral $\operatorname{sex}^{4}$ and oral sex and open-mouthed kissing are a risk factor for HPV-associated oral cancer. ${ }^{5}$

Dentists should take a history of oral sex from all patients, particularly young patients who present with lymphadenopathy and sore throat, and educate them about HPV-associated oral cancers as early detection provides better prognosis. Dentists should discuss and educate patients about HPV vaccination and prevention of HPV transmission.

Vagish Kumar L S, Mangalore, India

1. Saini R. Oral sex and oral cancer: a virus link. J Pharm Bioallied Sci 2011; 3: 467-468.

2. Chaturvedi A K. Beyond cervical cancer: burden of other HPV-related cancers among men and women. J Adolesc Health 2010; 46(4 Suppl): S20-26.

3. Dahlstrom K R, Li G, Tortolero-Luna G, Wei Q, Sturgis $\mathrm{E}$ M. Differences in history of sexual behavior between patients with oropharyngeal squamous cell carcinoma and patients with squamous cell carcinoma at other head and neck sites. Head Neck 2011; 33: 847-855.

4. Sathish N, Wang X, Yuan Y. Human Papillomavirus (HPV)-associated oral cancers and treatment strategies. J Dent Res 2014; 93(7 Suppl): 29S-36S.

5. D'Souza G, Agrawal Y, Halpern J, Bodison S, Gillison M L. Oral sexual behaviors associated with prevalent oral human papillomavirus infection. $J$ Infect Dis 2009; 199: 1263-1269.

DOI: $10.1038 /$ sj.bdj.2016.358

\section{CAREERS}

\section{The absence of restorative dentistry}

Sir, I was somewhat perplexed by the absence of restorative dentistry as a potential career pathway in a recent promotional piece in the BDJ In Practice (Which career is right for you? BDJ In Practice No. 11, November 2015). Rather curiously, 'implant dentistry' (which is not recognised by the GDC as one of their 13 specialist areas) was featured amongst oral and maxillofacial surgery, oral surgery, paediatric dentistry and orthodontics as 'one of the fastest growing branches of dentistry'. Granted, this piece appeared to be more about quietly advertising a sponsored careers day and the promotion of certain postgraduate programmes to appeal to the next generation of dentists. 'Promotions' such as these, however, add to the increasingly worrying trend of some young dentists believing that they can practise 'implant dentistry' in isolation and apparently become 'specialists' in this area. This is despite the increasing body of evidence on the biological complications and the associated challenges involved with this treatment modality. ${ }^{1-3}$

Dentists considering a career in secondary care might wish to explore the option of restorative dentistry, which is recognised as a GDC specialty, as a possible career. It integrates implant dentistry as part of prosthodontic treatment, as well as providing wider training in prosthodontics, endodontics and periodontics to help manage patients who require complex multidisciplinary care. These patients include, but are not limited to, those with oral cancer, hypodontia, cleft lip and palate, those who have suffered dental trauma, and managing the complex oral healthcare needs of the increasingly ageing population. Consultants in restorative dentistry support general dental practitioners in helping to solve complex problems of various kinds and offer leadership in the delivery of appropriate restorative care. It is a varied and interesting option for those seeking to follow an established GDC recognised career pathway rather than highlighting just one facet of it such as 'implant dentistry'

R. Chauhan, London

1. Derks J, Håkansson J, Wennström J L, Tomasi C, Larsson M, Berglundh T. Effectiveness of implant therapy analyzed in a Swedish population: early and late implant loss. J Dent Res 2015; 94(3 Suppl): 44S-51S.

2. Derks J, Schaller D, Håkansson J, Wennström J L, Tomasi C, Berglundh T. Effectiveness of implant therapy analyzed in a Swedish population: prevalence of peri-implantitis. J Dent Res 2016; 95: 43-49.

3. Giannobile W V, Lang N P. Are dental implants a panacea or should we better strive to save teeth? J Dent Res 2016; 95: 5-6.

DOI: 10.1038/sj.bdj.2016.359

\section{Bridging to medicine}

Sir, the Dental Council of India (DCI) has offered a solution to the acute shortage of medical doctors and specialists in India. It has proposed to start a bridge course for dental graduates so that they can become an MBBS doctor. There is already a bridge course for MBBS doctors who would like to become a dentist. The DCI president Dr D. Majumder has suggested a bridge course to help dental graduates to become MBBS doctors.

In India over 85\% of positions for physicians are vacant at community health centres, yet more than 15,000 dental graduates are jobless. The bridge course would be a good solution to both problems. ${ }^{1}$

Mahantayya V. Math, Yashoda R. Kattimani, R. M. Khadkikar, Mumbai, India

1. Sharda S. DCI bridge course to battle India's shortage of doctors. The Times of India, 9 April 2016. Available at: http://timesofindia.indiatimes. com/india/DCl-bridge-course-to-battle-Indiasshortage-of-doctors/articleshow/51758366.cms.

DOI: 10.1038/sj.bdj.2016.360 